\title{
Carbon Valuation: Alternatives, Alternations and Lateral Measures?
}

\author{
Steffen Dalsgaard
}

\begin{abstract}
This article refers to carbon valuation as the practice of ascribing value to, and assessing the value of, actions and objects in terms of carbon emissions. Due to the pervasiveness of carbon emissions in the actions and objects of everyday lives of human beings, the making of carbon offsets and credits offers almost unlimited repertoires of alternatives to be included in contemporary carbon valuation schemes. Consequently, the article unpacks how discussions of carbon valuation are interpreted through different registers of alternatives-as the commensuration and substitution of variants on the one hand, and the confrontational comparison of radical difference on the other. Through the reading of a wide selection of the social science literature on carbon markets and trading, the article argues that the value of carbon emissions itself depends on the construction of alternative, hypothetical scenarios, and that emissions have become both a moral and a virtual measure pitting diverse forms of actualised actions or objects against each other or against corresponding nonactions and non-objects as alternatives.
\end{abstract}

Key words: carbon credits; value; alternative; commensuration; climate change; market

\section{Introduction}

What does toasting 70 slices of bread have in common with heating 23 meals in the microwave? Allegedly the energy consumed by either of these actions emits as much $\mathrm{CO}_{2}$ as the difference between choosing to drive $10 \mathrm{~km}$ in a car instead of travelling the same distance by bus in Denmark. These were the figures communicated in a 2012 advertising campaign called 'Become world saviour', which was conducted by the Danish bus company Midttrafik. ${ }^{1}$

\footnotetext{
1 In Danish: bliv verdensredder.
}

Steffen Dalsgaard, IT University of Copenhagen, sdal@itu.dk.

(C) 2016 Authors

LiU Electronic Press, DOI 10.3384/VS.2001-5992.164167

http://valuationstudies.liu.se 
These rather innocent comparisons of mundane actions in terms of their quantified emissions appear frequently in explanations of how measurements and control of $\mathrm{CO}_{2}$-or 'carbon' as it is often referred to in everyday English usage-is central to achieving greenhouse gas (GHG) emission reductions. As such, the comparisons point to the pervasiveness of what I here refer to as 'carbon valuation'. I take this to be the economic and moral assessment and ascription of value to objects and actions based on their impact on the global climate measured in terms of carbon emissions, ${ }^{2}$ and the purpose of this article is to study how such comparisons constructed by carbon valuation are interpreted through different registers of alternatives. The bus company uses emission comparisons that are recognisable to Danish citizens as a marketing ploy, and it is exactly their recognisability that demonstrates how pervasive carbon valuation can be, when everyday actions can be assessed in terms of a universal emissions denominator. The question is: what is performed by the comparison and which logic is behind the operation? My argument is that even though the intention of the bus company is one of illustrating the climate costs of some actions compared to others, it exemplifies how the logic of carbon valuation builds upon the potentiality of substituting different alternative actions for each other. In this way, it addresses one of the central operations behind carbon valuation, namely an alternation between actions and non-actions, objects and non-objects, actual and potential that simultaneously plays on commensuration and differentiation of these alternatives (Dalsgaard 2014).

To approach the topic of carbon valuation, I look at two different understandings of alternative that can be discerned in the social science debates about carbon markets and credits and their potential for commensuration. These are alternative in the sense of being a variant of the same kind, where one can substitute for the other, and alternative in the sense of being an option that promises to be a radically different and incommensurable alternative to something. The meaning of the notion of 'alternative' is that it always requires a distinction of two realities, one deemed altered and the other unaltered, one chosen and the other not chosen. They are in principle mutually exclusive. For carbon valuation, however, there is a process of alternation between the altered and the unaltered (the 'business as usual'), where at times they are brought to be commensurable and at other times not depending on the circumstances and the actors involved.

This substitution of emissions finds its most visible form in carbon markets and carbon credits, which refer to one actor's purchase of emission permits, constructed from another actor's 'promises' not to emit. Promises refer to alternative intended reality of actions or

2 This is measured as 'global warming potential' with the base unit being one tonne of carbon dioxide equivalent ( $\mathrm{tCO} 2 \mathrm{e})$. 
material forms that do not yet exist (and may never come into existence). In order for them to reduce emissions, they must be somehow actualised. This means that the virtual emissions (established by a contract or other 'certified promises' of action or non-action) and the actual emissions are not only compared; their value is also made commensurate via trading with the consequence that the virtual and the potential impacts on the actual and the real (see Lohmann 2011). One could argue that promises always do that, although rarely in a linear and directly exchangeable way (cf. Beckert 2016). That is nonetheless the case when carbon valuation allows for the trade of actual with 'hypothetical' future emissions and ascribes value to potential scenarios at par with actual scenarios across global space and time. This way of dealing in alternatives results in carbon being identified and measured in all the material forms within which this atom might be embedded (in the ground, in forests, etc.), and in the actions that affect these material forms. Carbon valuation thus offers endless opportunities for discovering alternatives between carbonemitting actions, and it relies on breaking down any ontological separation between the actual and the virtual.

In what follows, I approach the topic of alternatives with inspiration from Bill Maurer's (2005) notion of lateral reasoning and his discussion of alternative currencies. Laterality refers to how ethnographic work (but also other forms of social-scientific activity such as the making of carbon credits) may not provide a metaperspective, but lies 'alongside' the social world and the relation between representation and 'reality' that it tries to analyse. Maurer demonstrates this by focusing on attempts by individuals and institutions to employ alternative currencies to forge anew an 'adequate' connection between monetary and economic value on the one hand and the social reality this value aims to represent on the other. The article is thus largely a scholarly commentary, where different positions on carbon trading are discussed in light of carbon valuation and the creation of alternatives. I will begin by outlining how the topic of alternatives can be approached with inspiration from Maurer. This inspiration will lead to a look at the limits to alternatives (around notions of incommensurability), then to the importance of certifications and materiality for establishing the commensuration or conversely the separation of the actual and the virtual, and lastly to how carbon credits are thus a matter of 'adequate' representations.

\section{Lateral Reasoning and Alternatives}

Since any conception of an alternative necessarily depends on its being different from what it is an alternative to, it also has to rely on a discussion of 'difference'. This is one of the underlying themes of Maurer's (2005) book, which draws upon the way that anthropology 
(and North American anthropology in particular) has relied on 'otherness' or difference as one of its main tropes, although to Maurer it is a matter of what constitutes currencies as 'different' from each other. Anthropological discussions in the 1980s and 1990s tried to strip cultural difference of any sort of essentialism and avoid taking its boundaries for granted in ethnographic descriptions and analyses. Still, anthropologists have had difficulties escaping the view of cultures in plural as radically different and incommensurable since is difficult to identify a neutral and non-partial vantage point, when the researchers themselves are in a position characterised by difference from what they investigate. Much anthropology relies on cultural phenomena as a multiplicity of differences (there are different cultures, different values, etc., each with its own history and context), which implies that the phenomena that are different are of one kind (e.g. they are all cultures). Difference thus becomes a matter of degree, and the phenomena are to some extent 'complementary' (see Maurer 2005: $25)$; variants of an otherwise homologous type. Instead of getting entangled in debating cultural relativism, Maurer's approach is first and foremost empirical - to understand the expressions of difference in the many voices and views of his material. Yet, to do this he also proposes in line with a tradition of thinking from Bergson and Deleuze to locate difference 'within the realm of the potential' (ibid.: 12). If one considers difference as having a temporal and emergent character-as difference being in kind as a virtual and continuous multiplicity-then difference points to a multiplicity of reality that becomes non-essential and non-static. 'Virtual reality' can be distinguished from 'possible reality', where 'the latter [is] always taking the form of the real while the former's actualization puts into question that prefiguration as it continually multiplies' (ibid.: 13). Difference is thus not a matter of comparing distinct and enumerable entities (a static number of 'different cultures') but allows Maurer to think 'laterally' alongside his interlocutors. This move involves sensitivity to the way a research approach is intertwined with that of the interlocutors, where difference and sameness 'alternates' (in the sense of 'oscillation' or 'circulation'), and it allows one to think of a non-static potential 'alternative to' (which implies the question of whether the phenomenon being studied is adequately conceptualised as a matter of for example 'culture' or 'value').

Thinking alongside but also 'across' to radical difference-letting carbon valuation circulate or alternate between oppositions-can in turn help us question the meanings of 'alternative' under specific circumstances (Maurer 2005: 16). The notion of radical difference implies incommensurability and irreducibility, whereas alternative in the sense of variant implies substitutability. Both of those meaningsand the relationship between them-are important to take into consideration in order to take lateral reasoning about carbon valuation 
seriously. How do carbon valuation practices and the actions they value become commensurate and thus substitutable variants? How do alternatives become radically different? The calculative techniques and measurements behind the making of credits, offsets, or actions that need to be offset, are supposed to impose commensurability and thus alternation in the sense of substitutability across a wide range of carbon-emitting actions and processes. For example, the comparisons in the beginning of the introduction are contained within the reasoning of a system of market-based carbon valuation-that different forms of emissions become commensurable and substitutable for one another across space and time (cf. Knox-Hayes 2010, 2013) ${ }^{3}$-even if it is unclear to what extent actions relating to cooking and transport really substitute for each other in anyone's everyday life.

\section{Carbon Markets and Commensuration of Difference}

Carbon trading and carbon markets basically come in two types. Compliance markets are created from national, regional or international regulations that impose caps or limits on emissions from industry. In order to avoid fines, industrial actors covered by these regulations can trade for extra credits, or they can sell their own excess credits. Voluntary markets are driven by demand from corporations with marketing strategies of corporate social responsibility but also from private consumers wanting to reduce their carbon footprints.

Both types of markets rely upon alternatives at different conceptual scales and parameters, and they promise to put into place several alternative futures: global warming mitigation, 'green' or 'clean' capitalism, revaluation of nature, human action, energy and so on (e.g. Bridge 2010; Newell and Paterson 2010; Newell et al. 2012). These are alternatives in the sense that they articulate possible trajectories that are considered as significantly different from the path undertaken by reality if left unaltered. Emission markets are first and foremost the outcome and performance of economic politics and it has been argued that, as such, they displace conflict and shift focus from pollution and responsibility to the technical rules of an incentives mechanism. Carbon trading might prove not very successful in fighting climate change, but as argued by Donald MacKenzie it is successful in 'technicizing' the politics of allocation and valuation of emission allowances (MacKenzie 2008: 6). The economic logic behind carbon markets builds on the assumption that GHGs affect the earth's climate equally no matter where the emission takes place (e.g. Grubb 2003:

\footnotetext{
3 In fact, 'emissions reductions have neither real space nor real time because the emission never occurs. The reduction is rather a mere reflection of the counterfactual, of what might have otherwise occurred. Both its space and time must be constructed' (Knox-Hayes 2010: 956).
} 
146; Victor and House 2004: 56; Yamin 2005: xxix). ${ }^{4}$ This reduces the problem of climate change to the problem of how to value and price carbon emissions (and other GHGs) correctly (see Grubb 2003; Stern 2006). More importantly for my argument, it enables alternation to operate through a global substitutability of a carbon credit for that which has to be offset or credited; of one tonne of $\mathrm{CO}_{2}$ for any other (or for an amount of $\mathrm{CH}_{4}$ or another GHG that can be calculated to have the same effect on the climate as one tonne of $\mathrm{CO}_{2}$ ).

When emissions trading is based on this logic of substitution, then one actual action in one part of the world is both in theory and in economic practice made commensurable with, and alternative to, some other action, which emits, reduces or promises not to emit an equivalent amount of GHG. Both the operations behind the mundane substitutions mentioned in the introduction, and the alternative 'environmentally friendly' capitalism that they entail, are often seen as condemning nature to be valued in economic terms, which excludes other forms of value that may be incommensurable with economic logic (Dalsgaard 2013). That is, valuing actions in this way does encounter resistance, because these actions are carried out by actors who value what they do for reasons (socially or culturally) that are not always reducible to a single measure of worth-they can be alternatives to each other in ways that rather express radical difference. To examine the depths of such critiques, I will briefly discuss how they as alternatives relate to the notion of commensuration in the sense of a process or 'a system for discarding information and organising what remains into new forms' (Espeland and Stevens 1998: 317).

Maurer does not explicitly mention commensuration, but it is nonetheless inherent to his work through discussions of for instance equivalence. Commensuration is for Wendy Espeland and Mitchell Stevens (1998) regarded as a form of valuation that creates relations between objects that are compared but also has the power to transform that to which it is compared (see also Muniesa 2012: 26). It can turn qualities into quantities and difference into magnitude (Espeland and Stevens 1998: 317). It has been argued that operations of commensuration of the carbon markets can translate into 'making things the same' (MacKenzie 2009). Radical difference is discarded when a specific action becomes stripped of context and represented in quantified form as an amount of carbon emitted-a new form where initial difference is no longer recognised.

Radical difference implies incommensurability, but its definition and its process of creation still depends upon a reference to its

\footnotetext{
${ }^{4}$ Location (horizontally or vertically in the atmosphere) and timing (e.g. season) of emissions actually do matter for the global warming potential in specific chemical, physical and meteorological environments, which is something designers of carbon markets have tended to ignore (Berntsen et al. 2006).
} 
opposite terms-and, therefore, a relation towards that to which it claims to be incommensurable. Drawing upon the work of Vivian Zelizer, Espeland and Stevens argue that:

the importance of incommensurable categories $[\ldots]$ depends $[\ldots]$ on the relative status of their oppositional form, commensuration. The extension of commensuration into more spheres of life may make incommensurable categories more meaningful, their defense more necessary. This extension may produce paradoxical effects, as when pricing children in law, labour and insurance shifted the terms of their value from primarily economic to moral and emotional. Children became priceless. (Espeland and Stevens 1998: 327)

It is difficult to say, for carbon trading, whether claims to pricelessness are strategic forms of political resistance (as in the critiques mentioned above) or inherently tied to the pricing of emissions. When emissions are priced and traded in voluntary markets for instance, one can suppose the existence of actors who prefer paying for credits rather than reducing their emissions. These 'preferences' may include private habits or routines that are deemed unavoidable or difficult to put a price on, but which can be preserved by pricing emissions instead.

This discussion of alternatives as either commensurable or not opens for a nuanced understanding of the carbon trading schemes as valuations in several different ways by making 'use of contrasts and differences, to gain insights from incomparability and inadequacy' (Schmidt 2008: 357). Part of what becomes clear from this lateral alternation is that valuation is as much created in the conversion or in the comparison of alternatives. It is not solely discernible as an ascribed quality stemming from how people consider it (e.g. its social and symbolic value), or a matter of the inherent affordances of the object valued (such as its material properties), which has been the two main positions in the debates about the value of currencies (see Maurer 2005). Value stems from the act of considering and valuing. That is, the focus shifts to valuation as a performed action or practice (Muniesa 2012). Exemplary here is how Heather Lovell (2014) draws upon Espeland and Stevens and other sociological literature on standards to discuss the process of making financial accounting standards for emission allowances in the UK. Problems with the work of commensuration and standardisation appeared in this sector because there was no certain ideal or normal mode of valuing the emission allowances (ibid.: 8-9). Some of Lovell's respondents aimed at a stabilisation of the emission categories, while others expected the categories to constantly evolve and sought what was practically feasible in the specific local embeddedness of markets. It is easy to think that another part of the reason for the difficulty is that the measurement of emissions affords an almost unlimited process of substituting alternative actions for one another, which I will return to in the next section. 
Carbon valuation encounters resistance when exposed in this way to entities that are difficult to quantify, or refuse to be reduced to an emission value at all, when quantity itself becomes a quality of things (Maurer 2006: 25), or where the commensuration is fraught either morally or in terms of what is accounted for. As Elizabeth Povinelli has noted about language use, incommensurability refers to a state in which two phenomena (or worlds) cannot be compared by a third without producing serious distortion' (2001: 320). Indeed Janelle Knox-Hayes has noted about the effects of carbon valuation schemes that 'the assumptions and frames of accounting have a significant and often distorting influence on the evaluation of greenhouse gas impact.' (Knox-Hayes 2013: 122), because 'the markets account for neither information complexity nor spatial scale and temporal duration under which environmental systems operate' (ibid.: 125; see also MacKenzie 2009; Bastian 2012). Knox-Hayes's overall point is that the financialisation of carbon emissions is a form of time-space compression, which divorces the use value of resources associated with the carbon emitted from the exchange value of the financial instruments (credits). This entails a separation of exchange value from its material context (nature), which creates distortions and demands for accelerated rates of resource production out of line with the natural processes underwriting production-even if carbon trading was meant to solve the discrepancy between human economic activity and build-up of GHGs in the atmosphere.

In the following sections, I will pursue some of these themes in more detail and discuss how they relate to carbon valuation as alternatives. This includes valuation from making commensurability between credits but also the defence of the incommensurability of actions and practices associated with or represented by carbon emissions. As a result, the discussion will begin with the exploration of carbon valuation's limits through the markets.

\section{Carbon Markets and Limits to Substitutions?}

Marketisation of carbon emissions would avert global warming by making it profitable not to emit GHGs. This has been the position of liberal economists like Nicholas Stern, who argue that climate change is the result of a market failure and of the failure of taking into account the full (environmental-economic) costs of human activity and impact on climate (Stern 2006). A starting point for economic thinking is then to consider what it could mean to take into account the 'full' costs. Is it necessary or even possible to think about full commensuration? And would this deny any space for alternatives to economic carbon valuations? Carbon (the atom) is so pervasive-it is the basis for life itself, and all human (and many non-human) actions emit carbon-that it may be just as important to explore the limits to carbon valuation, and ask what it is not an alternative to. Since every 
human action requires energy, which then causes the emission of various amounts of $\mathrm{CO}_{2}$, it could be difficult to identify the limits of what should count as carbon emissions. In the end it seems like a practical problem of what is measurable and at what aggregate scale of significance. What one makes of carbon (as a credit, as a form of value or a form of valuation) depends on what scale and what comparison one mobilises when trying to describe it and understand it (Simons et al. 2014).

The permeability of carbon allows for the construction of the global scale needed for carbon trading to work in the liberal economist's rhetoric about climate change. Where emissions circulate in the atmosphere, the markets promise an equal circulation of carbon in the form of credits. It seems pertinent to take the dual permeability of carbon seriously and follow emissions-laterally-across as many social and natural divides as possible to identify where and how carbon valuation happens, and in what way alternatives are generated and juxtaposed. When economists insist that carbon trading should be global, because 'from an atmospheric standpoint' carbon emissions know no boundaries and location of emissions do not matter (despite the scientific evidence to the contrary ${ }^{5}$ ), then neither should our analysis be deterred by the differentiation enacted by boundaries, but should rather pay attention to how carbon valuation both constructs and deconstructs them, and how the two different meanings of alternative emerge in the process.

Marxist-inspired scholarship has been especially critical of the economics of carbon valuation and has stressed especially the social limits to its scope. It has discussed how carbon has been incorporated into the capitalist world system, which has revealed the contradictory aspects of the alternatives created through these processes (see especially McMichael 2009; Lohmann 2010). For example, when the carbon credit is objectified as the means of finding alternative ways of organising the economy in order to mitigate global warming, it is presented as an alternative to accepting the current economic conditions that lead to climate change, and it is a way of perceiving the curbing of emissions through market-driven procedures as an alternative to state-organised taxation or command-and-control mechanisms (see Bumpus and Liverman 2008: 131). Yet with carbon valuation being at the centre of climate capitalism (Newell and Paterson 2010), it is embedded in an alternative variant of the contemporary economic system rather than proposing an alternative to it (e.g. Lohmann 2010; Dalsgaard 2013). 6

\footnotetext{
5 See n. 4 (Berntsen et al. 2006).

${ }^{6}$ One could argue that Marxists generally have propagated visions of society based on radical and revolutionary alternatives rather than accepting mere variants.
} 
Carbon valuation offers to make everything commensurable in its own terms (Dalsgaard 2013), but what about other terms? That is exactly the problem that emerges from positing carbon as an alternative valuation; it has been criticised by some scholars (e.g. Lohmann 2010) as posing as a quasi or even a pseudo-alternative-an alternative 'green' capitalism perhaps, but not an alternative to capitalism; carbon valuation schemes rely on one meaning but not the other. These critical scholars stress how carbon trading embodies the characteristics of uncertainty markets and risky financial products such as derivatives (Cooper 2010; Lohmann 2010; Spash 2010); it permits societies in the global north to maintain luxurious lifestyles and to rely upon fossil fuel-based unlimited growth rather than turning them towards the 'true' alternatives of recycling and renewable energy (Lohmann 2009a, 2010; see also McMichael 2009); it turns nature into an object that can generate profit (e.g. Knox-Hayes 2010), and comparing 'old and new carbon economies [...] redraws the boundary of the "carbon problem": climate change becomes no longer an emission problem or a sequestration problem, but one of carbon throughput' (Bridge 2010: 822), or one of managing fluctuation within the climate as much as within the economy (Cooper 2010).

Both the view of carbon valuation as posing quasi- or pseudoalternatives and the challenge with the emphasis on fluctuation or throughput become even clearer when it comes to the potential substitution of different mundane actions based on their cost in carbon emissions. Comparing the use of a microwave oven with the use of public transport is a pseudo- rather than a quasi-substitution. It is merely illustrative of the scale of emissions, and it is probably only intended as such; but by comparing the two it is also implied that one can make up for one's transport-based emissions by dropping some other-meaningful-activity. But who would-in his or her everyday life-be confronted with the choice of exchanging or sacrificing the use of a microwave for the privilege of driving a car rather than using public transport? Carbon valuation and in particular the carbon credit here exemplifies a scheme, which enforces connection, commensuration and pricing of 'events, states or goods that are not commensurated or priced in everyday life' (e.g. Lohmann 2009b: 522). Everyday actions like these are meaningful in relation to multiple cultural or social concerns and networks; they are often (radically) different without being substitutable.

If all carbon emissions according to economic discourse are commensurable and replaceable (any quantified emission negated is equal to any other emission of the same type and quantity), the question is how to identify the relationship between this understanding of carbon as generic (and universal) and the actualised and specific understandings of carbon emitting actions valued in different contexts and networks or being transformed as it crosses boundaries. Maurer's 
exploration of money as a parallel also notes how one line of thought (e.g. Georg Simmel) sees money as homogenising 'acid' that erodes human values, whereas others (such as Vivian Zelizer) 'draw attention to the myriad kinds and multiple effects of money' (Maurer 2005: 103). That is, if we see and expect to see carbon emissions and thus carbon valuation everywhere, the danger is that we easily end up glossing over the incongruent and incommensurable capacities that may emerge when exchanging different discursive or biological carbon compounds one for another. When these carbon compounds correspond to or represent each their own set of mundane actions, one then trades a congealed or contractual form of the actions or activities in question, when trading credits. However, trading actions in this congealed form as carbon offsets or credits illustrates how the moral values, which are associated with carbon reductions in one location (consumers or corporations eager for good conscience or PR), become 'disentangled' from their local context, when they are turned into a delimited commodity (see Thomas 1991). This is not to imply in a simple manner that some actions are moral and others not, but merely to state there may be multiple moralities attached to or detached from actions at any given time, and they shift through processes of exchange or commoditisation. The carbon markets have, nonetheless, brought about what seems to many observers to be bizarre emission reduction schemes. When the reduction for instance is based in rural India on the substitution of manually operated treadle water pumps for dieseldriven ones, then the abstracted substitution of emissions is accused of transmuting into a morally problematic discursive guise of 'luxury emissions' versus 'survival emissions' as Agarwal and Narain (1991) famously named it, or as 'bearing the white man's burden' as an Indian newspaper stated (Blok 2010: 20). Other examples include carbon funding for hydropower dams that destroy sustainable and lowemission local systems of water control and irrigation (Lohmann 2009a: 1070-1071), or oil palm plantations or similar mono-cropping that replaces rainforest based on the view that palm trees also absorb carbon from the atmosphere (Creagh 2010).

While substitutable on paper, not all emission reductions are attractive to western consumers and corporations, when what they want is to save the rainforest and its biodiversity, or improve health in the global south by introducing fuel-efficient 'clean cookstoves' to poor households so they need less firewood and the housewives do not inhale as much smoke from firewood (see Peters-Stanley and Gonzalez 2014: xiv). Where both of these examples play with the avoidance of negative alternative futures (no more rainforest; deterioration of poor people's health-disregarding the likelihood that such futures may occur anyhow), carbon trading here poses another level of alternative by being juxtaposed to and substituting for exchange relations between global north and global south in the field of development. 
Climate change mitigation and environmental policy is deeply integrated in this field today, where 'non-carbon benefits' was in focus at least prior to COP21 in Paris in December 2015. In fact, carbon offsetting does not appear to be much about the carbon but all about the other values that carbon-reducing projects realise or actualise (such as the relationship between humans and nature or living a 'green' consumer lifestyle). Attachment to such 'other values' is one of the parameters, which differentiates alternate types of carbon units or credits from each other (see Dalsgaard 2014).

While the use of carbon valuation for alternative ends thus seems abundant, debates about policies and market structures still only address a limited view of the alternative forms which emerge from the carbon valuation schemes. My argument is that when shifting focus to the actual and practical construction of carbon credits or emission allowances, it becomes clear that they rely on the manipulation of 'alternatives' at another more technical and sometimes material levelthat of the credit itself.

\section{Carbon Valuation and Certification: What is the Materiality of Credits?}

The value and alleged reality of carbon emission reductions expressed through carbon credits depends to a high extent on the work of certification. This section will go into some detail with this work, since the topic touches upon the way the 'reality' and commensurate potential of carbon is ensured through either its informational or its material forms, and whether these forms are regarded as substitutable or not. This paves the way for a discussion of effects and adequacy of credits valuation in the final section.

An important aspect of carbon valuation is the distinction between different kinds of credits. While all credits on paper are the same and nominally refer to an emission reduction of one tonne of $\mathrm{CO}_{2} \mathrm{e}$, some credits are more highly regarded than others, because it is deemed more likely (in part due to more rigorous certifications) that they adequately represent this. Different credit types can thus be seen as variants of the same kind, ideally substitutable for one another, but in practice they are valued differently and even carry different prices, which again means that commensuration is not straightforward or meets resistance even within the system of market valuation.

The categorisation made in financial accounting is one way of establishing the relation between credits, their degree of sameness or difference, and whether they can be substituted for each other or not, or through which factor of conversion (see Lovell 2014). Certification methodologies lie behind how the credits are made in practice. Certification not only claims to guarantee that a credit refers to a 'real' emission reduction, it also establishes differentiation between the different types of credits that all depend on different relationships as to 
how their reductions have come about, and how likely are their 'realities'. Where for instance the credits named Certified Emission Reductions (CERs) have to live up to standards ensuring that it is appropriate for trading in the strictly regulated compliance markets, Verified Emission Reductions, or Voluntary Emission Reductions (VERs) as they are also called, are made for voluntary markets, where there are fewer requirements.

The difference between voluntary and compliance markets and their respective credits has been reviewed extensively in the literature, including discussions of the different types of emission reducing projects and the making of standards (e.g. Bumpus and Liverman 2008; Corbera et al. 2009; Lovell et al. 2009; Lovell and Liverman 2010; Lovell 2014). The main point for my case is that the valuation employs different but comparable knowledge-making practices that make different claims about the relationship between carbon credits and reduced emissions. Heather Lovell and Diana Liverman (2010) have argued that credits for the compliance markets are largely constructed from the calculative practices of accounting with little or no trace of the conditions by which they are produced (cf. MacKenzie 2009), whereas credits in the voluntary markets often retain a link across the supply chain to the site of production in order to allow narratives to promote the buyer's ethical profile (see Lovell et al. 2009). Examples of the latter are credits referring to clean cookstoves or forest carbon sinks, which are popular because they appear tangible and are easy to communicate to the buyer (Stephan 2012).

Consequently, some scholars have argued that all types of carbon credits are constructed as commodities purely from information (e.g. Knox-Hayes 2013: 122). The underlying reason for this is that the carbon credit is not a physical or material commodity, but a representation of an event or action that affects materiality. The credit is thus a certificate that documents that this has happened, or rather has not happened, and that 'something equivalent' is allowed to happen. Carbon credits claim to be a reflection or representation of emission reductions, or non-existing emissions. As such they have no physical manifestation except in infrastructures as for example exchange platforms or registries, where they can be identified by a unique serial number (Knox-Hayes 2010: 957-958). In this regard, the certified credit has parallels to legal contracts as mentioned in the introduction and in the previous section (that is, an exchange of conditional actions materialised or congealed in information such as ledgers, formulations and signatures), and legal scholars have been active in interpreting the frameworks for the carbon markets and their products (e.g. Hepburn 2007).

Carbon credit information consists of the mapping of an alleged physical reality that affects the amount and value of the credits. It is for instance well documented how carbon emitters such as 
corporations (e.g. Lippert 2012, 2015) and carbon reduction projects (e.g. Ehrenstein and Muniesa 2013) basically claim to construct carbon emissions based on information about material assets and their use. This can be information that accounts for the polluting activities of a corporation that seeks to offset its emissions, or it can be information based or on the mapping of rainforest 'carbon sinks' (e.g. Stephan 2012; Ehrenstein and Muniesa 2013). However, even for credits referring to a clear image of a material reality, it is rather the counterfactual labour or actions that are done or not done to this material reality, which generates the value of the credits, which is why information (calculation as well as narratives) is so important (see Muniesa 2012; Lippert 2015).

Different types of markets and credits demand different forms of information, which in turn informs different modes of carbon valuation. Lovell and Liverman argue that 'information and knowledge about how the offset is produced-where and using what technology -is crucial within the voluntary offset market, in stark contrast to the compliance market where this type of information is actively dissociated from the credit' (2010: 260). The work to represent the reality of emission reductions within the voluntary markets includes attempts to present it in an almost customised form as 'boutique offsets' to consumers in the global north who are presented with and demanding ethical narratives of the good that offsets do even if misrepresenting the realities of how the credits are produced (Lovell et al. 2009; see also Ehrenstein and Muniesa 2013: 179). Apart from the different carbon 'units' (e.g. credits such as the CER or VER) subject to individual rules depending on which market the carbon is traded in (e.g. Button 2008: 573-574), there were besides that in 2009 at least 18 different standards ${ }^{7}$ for offsets, each claiming to guarantee the value of a unit and integrating its own gamut of social and environmental benefits, land use or forestry (Newell and Paterson 2010: 120-121; Descheneau 2012: 605). The voluntary markets are less strict in terms of certifications, but 'the offset narratives and technologies also act to reassure consumers about what it is they are buying, given the absence of both a tangible product and regulatory standards' (Lovell et al. 2009: 2358). In other words, adequacy may here refer to detailed stories rather than to accuracy in the methodologies behind the measurement of emissions.

The requirements and thereby the information needed to certify or verify a tonne of carbon usually focus on the capacity of projects to produce or store carbon. Focus is on the technical drafting of a project

7 This is not the same as the different emissions units such as AAUs (Assigned Amount Units), ERUs (Emission Reduction Units) and CERs (see e.g. Hepburn 2007: 380; Yamin 2005). There are today at least nine different standards for offsets (see http://www.carbonneutral.com/resource-hub/carbon-offsetting-explained/carbonoffset-standards, accessed April 4 2016). 
design document (PDD) which delineates (spatially as well as temporally) the project aimed at carrying out the reduction changes, calculates credible baselines or 'reference scenarios' to which the project will be compared, and estimates the carbon credits to be produced (Ehrenstein and Muniesa 2013). This work is done in order to argue and to make it plausible that the reduction is additional to a certain 'business as usual' scenario; in other words, what would emissions be like in the absence of the project? In this respect, the project design introduces the agency of some human individual or group, which earns the credits by changing a course of action, and it is the promise of this alternative course of action that provides both the reality and the value of the carbon credit. Note that project designers claim that additionality refers to 'alternative' in the sense of 'radically different' by promising a singular future that would otherwise not have come about rather than merely substituting one course of action for another.

The notion of additionality as an 'estimate of expected emission reductions' (Hepburn 2007: 381) provides food for thought here, because it stretches carbon valuation conceptually to both temporal and spatial limits. Additionality is very difficult to prove, and it is largely hypothetical in its reference to a business as usual scenario (e.g. Bumpus and Liverman 2008: 135-136); a calculation projected forward in time for the duration of the project based on known conditions of the past and comparisons to similarly contemporary scenarios. Critics would argue that the counterfactual alternative is thus often inadequate if not directly spurious, even if it is treated as having the same epistemic status as actual histories of emissions (e.g. Lohmann 2011). For a forest carbon project the expected growth rate of the relevant species of trees combined with vegetation density, soil nutrients, hours of sunlight and many other factors must be known or estimated for the specific location of the project (cf. Stephan 2012). The valuation itself is furthermore delicate, because the carbon credit is what occurs in excess of the natural absorption of atmospheric carbon by vegetation and soil, or it must be demonstrated that the project actively ensures a growth process that otherwise would be averted (Gutiérrez 2012: 53). It must also be guaranteed that the activities or processes that emit carbon are indeed averted and not just relocated, outsourced or exported. In the carbon project jargon this is called 'leakage' (Gutiérrez 2012: 54, see also Davis and Caldeira 2010). In other words, what is valuable is not any existing carbon, but would-be carbon; carbon that would or should have been emitted but was not. In some cases it exists in the mapping of carbon sinks-the storage of carbon-which is compared to the counterfactual and imagined alternative event that it will be released and would have been emitted unless some developer paid to conserve it. Emission reductions here become a virtual resource; not 'not-real' but not actualised either. 
It is always implied (if not always demonstrated) that carbon credits correspond to a substantial and material reality-both spatially and temporally present at a given duration in time for reversing emissions already done or for offsetting potential emissions in the future (see Bumpus 2012). The 'hot air' mentioned above is one example, though, where the materiality and reality of reductions is questioned, and the value of these credits is derived from an intergovernmental agreement. But also for other credits there can be doubt. Some of the more ideological positions on the US dollar lament that its value is no longer being fixed to and backed by the 'reality' of gold (Maurer 2005: 89), and similarly the centrality of the work of auditors and verifiers could indicate that the value of carbon credits depends on the social or socio-technical production of trust and signification rather than on actual material carbon (cf. Lovell 2014: 266). Indeed a patch of forest can be converted into potential carbon credits through documentation, so the materiality is not unimportant for adequacy of the representation and it functions as a persuasive aesthetic in the marketing of credits; but it is often far removed from what is being traded.

Having said that, from the perspective of 'social studies of finance' (see MacKenzie 2008), materiality is more important than usually imagined by those arguing that the value of carbon credits is purely informational or government fiat. Materiality in this view is not so much the 'reality' of the carbon-materiality that the credits strive to represent, or how the credits are embedded in an imaginary of the fluctuation of atoms and molecules in and out of the atmosphere. For the everyday practices of the actors involved, the point is more importantly how carbon (credits as much as emissions) is located materially in socio-technical infrastructures or objects that do not simply 'represent' a market, but is a constitutive part of economic action (ibid.: 3). Markets and their actors have materialityphysicality, corporeality and technicality-and both prices and credits take physical form. Credits are located and must be stored and moved through writing and electronic signals (ibid.: 2). These include online carbon calculators (Lovell et al. 2009) or spreadsheets for corporate carbon accounting, which constructs carbon emissions in need of offsetting (Lippert 2012, 2015). On the credit side, they include windmills that generate power (cf. Phadke 2012), and oil or coal that contain potential emissions (cf. Mitchell 2011), but also the technological infrastructures or 'datascapes' (Lippert 2015) that enable calculations and trading. These can be PDDs, registries and other digital and technological means of exchanging the credits with speed and efficiency, which keeps track of the lifecycle of the credit including origin, trading history and expiry (Knox-Hayes 2013: 124). KnoxHayes emphasises the problem of how to locate the 'reality' and the value of carbon, though, in that 'the markets seem to instantly create 
global scale and tremendous value, because they create value for events absent space and time, and it is therefore difficult if not impossible to ascertain the place and scale at which the value actually exists' (KnoxHayes 2013: 124). Valuation, and the adequacy of that valuation, is thus distributed upon a diversity of materialities and actions as much as virtualities and non-actions, which means that both the actualisation of its 'reality' and value is constantly emerging and changing, and difficult to locate.

What this section has demonstrated is that alternations between materialisations of carbon and information about carbon exist in a complex but mutually reinforcing relationship of potential alternatives, and that carbon is difficult to 'locate' as its status and hence location can be mobile in the physical as much as the socio-technical world. Along with socio-technical infrastructures, certification work with its focus on additionality and counterfactuals in project design provides attempts to stabilise the alternation, to ensure the process of substitutability between alternatives (such as different types of credits). Yet it is argued by critics to contain a spurious assumption of actual and virtual emissions being equivalent, due to the uncertainties of what counts as 'additional' or what reality can be ascribed to a counterfactual. This brings us to the question of 'adequacy' of the representation of the alternative and virtual scenarios potentially substituted through the carbon credit. This is an aspect of carbon valuation, where Maurer's work on the adequacy of alternative currencies provides a useful starting point.

\section{Debating the Adequacy and the Effect of Carbon Valuation}

Maurer's project is to study alternatives to modern money and finance as they are envisioned and made in practice by a wide range of actors. His analysis is intertwined with reasoning and 'everyday understandings of money among people who are forging their own modes of finance through Islamic banking and non-state-based alternative currencies' (2005: xiii); people who have been active in trying to rediscover in practice the relation of money to 'reality', so it can be 're-grounded' and (again) conform to social order whether it be faith, community or law (Maurer 2005: 6-7). Not disregarding the difficult philosophical problem of how to approach or discuss what reality 'is', I take inspiration from Maurer's lateral way of addressing it, which is to focus on how the carbon value debate is concerned with the practical 'adequacy' of the representation; how to bring 'one's concepts in accord with reality' (ibid.: xiii).

How adequacy is an empirical matter of debate for this topic is exemplified by the discussions over the establishment of standards for carbon credits in the financial accounting mentioned above (Lovell 
2014). The desire to make value 'real' and to make 'the real' valuable has a parallel in carbon valuation. To be valuable, a carbon credit must be certified as representing one tonne of $\mathrm{CO}_{2} \mathrm{e}-\mathrm{a}$ carbon reduction that is 'real, measurable and additional' (Hepburn 2007: 381), which I touched on in the previous section. Suffice it to say here that the carbon emissions represented by a credit should exist as an effect somewhere 'in the real world', outside the circulation of finance with its credits, allowances and offset units on paper. Such references to reality should be taken seriously as empirical phenomena that have an effect in themselves. Whether and how this carbon and its effect 'out there' exists is an ongoing debate, which has generated an industry of carbon auditors doing calculations, measurements, risk assessments, certification, verification, monitoring and reporting of practices in terms of their alleged emissions or non-emissions.

A fundamental insight here is to appreciate that carbon valuation schemes, like other economic schemes, in Donald MacKenzie's (2006) terms operate as 'engines' rather than as 'cameras'. Economic theory assumes that economic models depict or represent a detached reality. A more adequate perspective here would be to say that the valuation schemes are implicated in this reality; they form it and bring its shifting meanings into being (see also Maurer 2005: 53). This perspective allows for the dual meaning of 'alternative', and the effort of connecting value and 'reality' is shared by those multiple actors trying to figure out how to appreciate carbon in whatever form it appears in their everyday lives whether on paper, in trees, in energy consumption or something else. Frequently this relation is highly uncertain and disputed. Carbon valuation schemes involve attempts by multiple social actors to understand, interpret and value the world they live in, as much as it is an academic exercise based upon multiple forms of (disciplinary) knowledge including law, accounting, economics, biology, sociology and much more. In such a case and with such an object of study, the anthropologist can work laterally alongside the interpretations and social constructs of both scholars and lay people. The anthropologist investigates their explorations of carbon valuation to evoke the relevant meaning-making efforts, and to show how these efforts give rise to the tensions between different understandings of alternative.

The problem of how to value carbon credits, and conversely what carbon credits value, thus touches upon similar processes of valuation as the alternative currencies described by Maurer, and several scholars have attempted to make this comparison (e.g. Victor and House 2004; Button 2008; Descheneau 2012; Dalsgaard 2013). In what ways are carbon credits 'adequate' as signs in relation to the value backing them; whether value largely stems from government fiat and signification (as in compliance markets), from market demand or 'desire' (when traded as offsets in voluntary markets), or from material 
existence in nature and in the affordances of the substance in question (industrial emission measurements, storages in vegetation or in soil or certified reductions from development projects)? While critiques of carbon credits' efficiency in addressing climate change mostly comes from Marxist-inspired scholars, environmental activists and supporters of renewables (e.g. Lohmann 2010), the question of what is 'really' valued with a carbon credit does occupy the entire carbon trading industry. Where Maurer notes that 'scholars across the disciplines are continuously surprised to discover that money is 'just' meaning, or that finance is fiction' (2005: xiv), the problem seems to be the opposite for carbon. Policymakers, journalists and scholars alike have at least during the early days of carbon markets questioned both the soundness and the effects of carbon trading with metaphorical references to how carbon credits' value came out of 'thin air' due to the uncertainty of the definitions and measurements that back them up (Gutiérrez 2012), or that it was the trading of 'hot air'. 'Hot air' has referred either to an oversupply of dubious claims to reductions from projects in the global south (Michaelowa 2005: 298) or more frequently to the inflated allocations of emission allowances given for free to industries in Eastern Europe and the former Soviet Union as part of the 1997 Kyoto Protocol (Anderson and Bradley 2005; see also Grubb 2003: 166-167; Button 2008: 584-585; Spash 2010: 179).

Many of those involved, however, do believe in the work that is being done, and in other instances (the making of counterfactual baselines and modelling for estimating forest carbon) valuation practices have become naturalised and are by now taken for granted in many circles (Stephan 2012). Judging from the amount of work that goes into discussions for instance among financial accountants trying to identify standards for carbon credits (Lovell 2014), it may be that carbon trading in general has become an accepted policy and practice for adequately dealing with climate change in many circles; but the making of credits and how to deal with them remains a challenging and constantly evolving issue, because of the problematic and sometimes inadequate relationship between effect (in emissions) and representation of that effect (in credits).

\section{Conclusion}

This article has discussed how carbon valuation and its comparisons are interpreted through different registers of alternatives, and how this means that potential or virtual scenarios for emissions come to be valued as equal to actual and real emissions (including the actions and objects causing them). Contestations over carbon's value revolve around interpretations of these claims to alternatives as either substitutions or as radical differences. Carbon valuation provides alternative imaginaries in many respects (an alternative capitalism, 
alternative ideals for consumption, etc.), and as a market system it commodifies and trades in alternatives (alternative nature, alternative counterfactual reality, etc.), which can be interpreted either as genuinely different courses of action that avoid emissions or as mere substitutions of speculative courses of action for real emissions. When pushing the alternatives to their limits, it becomes clear how practices that emit carbon sometimes become construed as alternatives across what claim to be incommensurable criteria and along imaginaries that are detached from cultural practices of everyday life.

The alignment of alternatives is both the most promising aspect of carbon valuation as a way for a social scientist to understand how carbon markets are presented as solutions to climate change and the most problematic_-socially as much as technically-for the actors involved in reaching any such solutions. As with discussions of commensuration (Espeland and Stevens 1998) it is promising because it allows for comparisons and exchanges, and is problematic because those comparisons and exchanges gloss over differences that cannot be transferred without distortion. Also the potential for carbon markets to produce new alternatives has been debated by academics from different disciplines. Some have thought that putting a price on carbon emissions would spur on entrepreneurs to innovate in order to earn money on selling carbon credits through better and 'greener' technology; but critics have argued that carbon trading provided incentives not to develop innovation and alternatives amid those industries that can just pay their way out - those energy industries where it may be needed most (Lohmann 2009b: 507).

Much of the criticism of carbon valuation schemes has been levelled at commensuration as a common metric of quantification (e.g. MacKenzie 2009). It may not be the quantification as such that is the problem, though, but that carbon valuation quantifies actions, rights and objects that emerge as incommensurable and perhaps even 'priceless'. For example, one could speculate that carbon valuation ignores how human actions can be tied closely to preservation of the self, with identities, and that the practices that are valued in terms of carbon emissions can be perceived as 'inalienable' to individuals and groups (see Weiner 1992; Godelier 1999). This does not work for all actions, of course, but many are so habitually ingrained to a sense of self that they are hard to exchange for some alternative. Carbon trading also potentially values carbon emissions morally as part of 'nature'. Carbon is at the centre of conflicting ideas about 'the nature of nature'-in particular nature as object versus nature as (sacred) subject to which can be ascribed a certain inalienability that emerges as an effect of the commodification of nature. Then the alternative becomes one of resistance or one that engenders resistance. By constructing alternatives, carbon valuation does not only make 
potential substitutions-it also creates alternatives as radically different.

The discussions of carbon valuation are not likely to close any time soon despite apparent failures of the carbon markets to mitigate climate change (Stephan and Lane 2014). Perhaps there is little point, though, in assuming that the actors involved are trying to build an alternative 'perfect market' or construct an alternative global currency out of carbon credits (cf. Button 2008). It may be more important to recognise along the lines of valuation analysed by Bill Maurer (2005) how these actors strive to create 'adequacy' between the (carbon) valuation schemes, and the environmental costs of the activities in which we as humans are engaged, even if that is also in their view in some ways an impossible and never-ending endeavour. Achieving complete fungibility of carbon credits would break down radical differences, but it seems that other actors in response are trying to place boundaries around the relevant markets by 'stipulating zones of the incommensurable through social institutions, laws and informal practices' (Gudeman 2008: 161). Numerous actors have vested interests in valuing carbon, and instead of assuming that the discussions will reach an end point, they may entail an ever-expanding set of markets as new forms of carbon valuation are invented through laterally circulating experiments with nature, climate and the environment.

Acknowledgements. This article could not have been written without the moral support of Ton Otto, and it has benefited from discussion with him and several other colleagues, especially Michael Eilenberg, Christopher Gad, Casper Bruun Jensen, Ingmar Lippert and Annie Thuesen. I also owe thanks to Fabian Muniesa and two anonymous reviewers for Valuation Studies. The funding that has allowed me to develop this article has been provided by a Sapere Aude grant from the Danish Council of Independent Research.

\section{References}

Agarwal, Anil K., and Sunita Narain. 1991. Global Warming in an Unequal World. Delhi: Centre for Science and the Environment.

Anderson, Jason, and Rob Bradley. 2005. "Joint Implementation and Emissions Trading in Central and Eastern Europe." In Climate Change and Carbon Markets, edited by Farhana Yamin, 200-230. London: Earthscan.

Bastian, Michelle. 2012. "Fatally Confused: Telling the Time in the Midst of Ecological Crises." Environmental Philosophy 9(1): 23-48. 
Beckert, Jens. 2016. Imagined Futures. Cambridge, MA: Harvard University Press.

Berntsen, Terje, Jan Fuglestvedt, Gunnar Myhre, Frode Stordal, and Tore Berglen. 2006. "Abatement of Greenhouse Gases: Does Location Matter?" Climatic Change 74: 377-411.

Blok, Anders. 2010. " $\mathrm{CO}_{2}$-markeder-En Ny Form for Kulstofkolonialisme?” Global Økologi 17(4): 18-20.

Bridge, Gavin. 2010. "Resource Geographies I: Making Carbon Economies, Old and New." Progress in Human Geography 35(6): 820-834.

Bumpus, Adam. 2012. "The Matter of Carbon: Understanding the Materiality of $\mathrm{tCO}_{2} \mathrm{e}$ in Carbon Offsets." In The New Carbon Economy, edited by Peter Newell, Maxwell Boykoff, and Emily Boyd, 13-39. Chichester: Wiley-Blackwell.

Bumpus, Adam, and Diana Liverman. 2008. "Accumulation by Decarbonization and the Governance of Carbon Offsets." Economic Geography 84(2): 127-155.

Button, Jillian. 2008. “Carbon: Commodity or Currency?" Harvard Environmental Law Review 32: 571-596.

Cooper, Melinda. 2010. "Turbulent Worlds: Financial Markets and Environmental Crisis.” Theory, Culture \& Society 27(2-3): 167-190.

Corbera, Esteve, Manuel Estrada, and Katrina Brown. 2009. "How Do Regulated and Voluntary Offset Schemes Compare?" Journal of Integrated Environmental Sciences 6(1): 25-50.

Creagh, Sunanda. 2010. "Indonesia May Let Palm Oil Growers Collect $\mathrm{CO}_{2}$ Credits.” Reuters, 9 August. http://www.reuters.com/article/2010/08/09/ indonesia-palmoil-forest-idUSJAK33205320100809, accessed 28 July 2015.

Dalsgaard, Steffen. 2013. "The Commensurability of Carbon.” HAU: Journal of Ethnographic Theory 3(1): 80-98.

-. 2014. "Carbon Value between Equivalence and Differentiation." Environment and Society: Advances in Research 5: 86-102.

Davis, Stephen, and Ken Caldeira. 2010. "Consumption-based Accounting of $\mathrm{CO}_{2}$ Emissions.” PNAS 107(12): 5687-5692.

Descheneau, Philippe. 2012. "The Currencies of Carbon: Carbon Money and Its Social Meaning.” Environmental Politics 21(4): 604-620.

Ehrenstein, Véra, and Fabian Muniesa. 2013. "The Conditional Sink: Counterfactual Display in the Valuation of a Carbon Offsetting Reforestation Project.” Valuation Studies 1(2): 161-188.

Espeland, Wendy, and Mitchell Stevens. 1998. "Commensuration as a Social Process." Annual Review of Sociology 24: 313-343.

Godelier, Maurice. 1999. The Enigma of the Gift. Chicago, IL: The University of Chicago Press.

Grubb, Michael. 2003. "The Economy of the Kyoto Protocol." World Economics 4(3): 143-189.

Gudeman, Stephen. 2008. Economy’s Tension. New York: Berghahn Books. 
Gutiérrez, María. 2012. "Making Markets Out of Thin Air: A Case of Capital Involution." In The New Carbon Economy, edited by Peter Newell, Maxwell Boykoff, and Emily Boyd, 41-63. Chichester: WileyBlackwell.

Hepburn, Cameron. 2007. "Carbon Trading: A Review of the Kyoto Mechanisms." Annual Review of Environment and Resources 32: 375393.

Knox-Hayes, Janelle. 2010. "Constructing Carbon Market Spacetime: Climate Change and the Onset of Neo-Modernity." Annals of the Association of American Geographers 100(4): 953-962.

—_- 2013. "The Spatial and Temporal Dynamics of Value in Financialization: Analysis of the Infrastructure of Carbon Markets." Geoforum 50: 117-128.

Lippert, Ingmar. 2012. "Carbon Classified? Unpacking Heterogeneous Relations Inscribed into Corporate Carbon Emissions." Ephemera 12(1/2): 138-161.

- 2015. "Environment as Datascape: Enacting Emission Realities in Corporate Carbon Accounting." Geoforum 66: 126-135.

Lohmann, Larry. 2009a. "Climate as Investment." Development and Change 40(6): 1063-1083.

—. 2009b. "Toward a Different Debate in Environmental Accounting: The Cases of Carbon and Cost-benefit." Accounting, Organizations and Society 34: 499-534.

—. 2010. "Uncertainty Markets and Carbon Markets." New Political Economy 15(2): 225-254.

- 2011. "The Endless Algebra of Climate Markets." Capitalism Nature Socialism 22(4): 93-116.

Lovell, Heather. 2014. "Climate Change, Markets and Standards: The Case of Financial Accounting." Economy and Society 43(2): 260-284.

Lovell, Heather, and Diana Liverman. 2010. "Understanding Carbon Offset Technologies.” New Political Economy 15(2): 255-273.

Lovell, Heather, Harriet Bulkeley, and Diana Liverman. 2009. "Carbon Offsetting: Sustaining Consumption?" Environment and Planning A 41(10): 2357-2379.

MacKenzie, Donald. 2006. An Engine, Not a Camera. Cambridge, MA: The MIT Press.

- 2008. Material Markets. Oxford: Oxford University Press.

- 2009. "Making Things the Same: Gases, Emission Rights and the Politics of Carbon Markets." Accounting, Organizations and Society 34(3-4): 440-455.

McMichael, Philip. 2009. "Contemporary Contradictions of the Global Development Project." Third World Quarterly 30(1): 247-262.

Maurer, Bill. 2005. Mutual Life, Limited. Princeton, NJ: Princeton University Press.

———. 2006. "The Anthropology of Money." Annual Review of Anthropology 35: 15-36. 
Michaelowa, Axel. 2005. "Determination of Baselines and Additionality for the CDM: A Crucial Element of Credibility of the Climate Regime." In Climate Change and Carbon Markets: A Handbook of Emissions Reduction Mechanisms, edited by Farhana Yamin, 289-304. London: Earthscan.

Mitchell, Timothy. 2011. Carbon Democracy. London: Verso.

Muniesa, Fabian. 2012. "A Flank Movement in the Understanding of Valuation." The Sociological Review 59: 24-38.

Newell, Peter, and Matthew Paterson. 2010. Climate Capitalism. Cambridge: Cambridge University Press.

Newell, Peter, Maxwell Boykoff, and Emily Boyd (eds). 2012. The New Carbon Economy. Chichester: Wiley-Blackwell.

Peters-Stanley, Molly, and Gloria Gonzalez. 2014. Sharing the Stage: State of the Voluntary Carbon Markets 2014. Washington, DC: Forest Trends' Ecosystem Marketplace.

Phadke, Roopali. 2012. "Resisting and Reconciling Big Wind: Middle Landscape Politics in the American West." In The New Carbon Economy, edited by Peter Newell, Maxwell Boykoff, and Emily Boyd, 159-181. Chichester: Wiley-Blackwell.

Povinelli, Elizabeth. 2001. "Radical Worlds: The Anthropology of Incommensurability and Inconceivability." Annual Review of Anthropology 30: 319-334.

Schmidt, Robert. 2008. "Gaining Insight from Incomparability: Exploratory Comparison in Studies of Social Practices." Comparative Sociology 7(3): 338-361.

Simons, Arno, Aleksandra Lis, and Ingmar Lippert. 2014. "The Political Duality of Scale-making in Environmental Markets." Environmental Politics 23(4): 632-649.

Spash, Clive. 2010. "The Brave New World of Carbon Trading." New Political Economy 15(2): 169-195.

Stephan, Benjamin. 2012. "Bringing Discourse to the Market: The Commodification of Avoided Deforestation." Environmental Politics 21(4): 621-639.

Stephan, Benjamin, and Richard Lane (eds). 2014. The Politics of Carbon Markets. New York: Routledge.

Stern, Nicholas. 2006. The Economics of Climate Change: The Stern Review. Cambridge: Cambridge University Press.

Thomas, Nicholas. 1991. Entangled Objects. Cambridge, MA: Harvard University Press.

Victor, David F., and Joshua C. House. 2004. "A New Currency. Climate Change and Carbon Credits." Harvard International Review 26(2): 5659.

Weiner, Annette. 1992. Inalienable Possessions. Berkeley, CA: University of California Press.

Yamin, Farhana. 2005. "Introduction." In Climate Change and Carbon Markets, edited by Farhana Yamin, xxix-xliii. London: Earthscan. 
Steffen Dalsgaard holds a PhD in Anthropology and Ethnography and is associate professor in the research group Technologies in Practice at the IT University of Copenhagen. He has worked with perceptions of the state and government in Papua New Guinea, with the cultural aspects of electoral systems and politics, and more recently with the logic of carbon trading. Among his most noteworthy recent publications is the co-edited volume Time and the Field (Berghahn 2015), which rethinks the notion of the ethnographic fieldwork in terms of time rather than space. 